\title{
Improved specificity for detection of Mycobacterium bovis in fresh tissues using IS6110 real-time PCR
}

\author{
Tyler C Thacker ${ }^{1 *}$, Beth Harris ${ }^{2}$, Mitchell V Palmer ${ }^{1}$ and Wade R Waters ${ }^{1}$
}

\begin{abstract}
Background: Culture of M. bovis from diagnostic specimens is the gold standard for bovine tuberculosis diagnostics in the USA. Detection of M. bovis by PCR in tissue homogenates may provide a simple rapid method to complement bacterial culture. A significant impediment to PCR based assays on tissue homogenates is specificity since mycobacteria other than $M$. bovis may be associated with the tissues.

Results: Previously published IS6110 based PCR diagnostic assays, along with one developed in house, were tested against environmental mycobacteria commonly isolated from diagnostic tissues submitted to the National Veterinary Services Laboratory. A real-time PCR assay was developed (IS6110_T) that had increased specificity over other IS6110 based assays. Of the 13 non-tuberculous mycobacteria tested with IS6110_T only M. wolinskyi was positive. Thirty M. bovis infected tissue homogenates and 18 control tissues were used to evaluate the potential for the assay as a diagnostic test. In this small sample, IS6110_T detected 20/30 samples from M. bovis infected animals and 0/18 control tissues.
\end{abstract}

Conclusions: The IS6110_T assay provides a PCR based assay system that is compatible with current diagnostic protocols for the detection of M. bovis in the USA and compliments current testing strategies.

\section{Background}

Mycobacterium bovis is the causative agent of bovine tuberculosis. Isolation of $M$. bovis from tissues harvested from suspect animals remains the gold standard for diagnosis. Although bacteriological culture is a reliable, definitive method for detection of $M$. bovis it takes a significant amount of time. Detecting the presence of $M$. bovis DNA in tissues prepared for culture may provide a simple, rapid diagnostic method.

Mycobacteria other than M. bovis are routinely isolated from tissues submitted for diagnostic culture. These non-M. bovis mycobacteria may interfere with PCR diagnostic tests performed on these tissues if the test does not have sufficient specificity. Most PCR primer pairs published to date were designed for identification of mycobacteria that have been isolated by culture.

\footnotetext{
* Correspondence: tyler.thacker@ars.usda.gov

'Infectious Bacterial Diseases Research Unit, National Animal Disease Center, Agricultural Research Service, United States Department of Agriculture,

Ames, lowa, USA

Full list of author information is available at the end of the article
}

Use of selective media and biochemical tests can eliminate many non-M. bovis mycobacteria prior to PCR tests; however, PCR assays on tissues that may have non- $M$. bovis mycobacteria requires sufficient specificity to differentiate environmental mycobacteria from $M$. bovis.

To address this possibility, DNA from strains of mycobacteria other than $M$. bovis, that are routinely isolated from diagnostic samples, were tested for cross reactivity with the commonly used IS6110 PCR primer pairs used to detect M. bovis.

\section{Results}

\section{Specificity of PCR primers}

The following mycobacteria are routinely isolated from tissues submitted for $M$. bovis diagnostic culture at the National Veterinary Services Laboratories: M. smegmatis, $M$. terrae, $M$. goodii, $M$. fortuitum, M. kansasii, $M$. wolinskyi, M. simiae, M. peregrinum, M. intracellulare, M. chelonae, M. avium subsp avium, and M.avium subsp paratuberculosis. DNA from these strains were
C Biomed Central

ㄷ 2011 Thacker et al; licensee BioMed Central Ltd. This is an Open Access article distributed under the terms of the Creative Commons Attribution License (http://creativecommons.org/licenses/by/2.0), which permits unrestricted use, distribution, and reproduction in any medium, provided the original work is properly cited. 
used to determine the specificity of two previously published PCR primer pairs IS41/43[1] and IS6110[2]. Both sets of primers generated a PCR product for $M$. bovis, M. terrae, M. goodii, and M. wolinskyi (Table 1). The IS41/43 primer pair also detected M. fortuitum; whereas, IS6110 primer pair cross-reacted with $M$. peregrinum and M. chelonae.

\section{Development of real-time PCR primers with increased specificity}

The cross reactivity of previously published primers with commonly isolated environmental mycobacteria necessitated the development of primers with greater specificity. Primers and probe for real-time PCR were developed that targeted IS6110 (IS6110_T). The primers were tested for specificity using the mycobacteria described above (Table 1). The IS6110_T primer pair generated a PCR product from M. bovis, M. wolinskyi and M. goodii using conventional PCR; however, using the primers and probe in a real-time PCR assay resulted in a positive reaction to only $M$. bovis and $M$. wolinskyi (Table 1). A 317 bp region of M. wolinskyi and M. bovis genomes that contained the region amplified by the primers used in this paper were sequenced to determine if a test with higher specificity could be developed using this region. The amplified region from $M$. wolinskyi was $100 \%$ identical to that of $M$. bovis. Portions of the $16 \mathrm{~S}$ gene was sequenced to confirmed the identity of $M$. wolinskyi.

Table 1 Comparison of primer specificity using reference strains of Mycobacteria commonly isolated from clinical samples

\begin{tabular}{|c|c|c|c|c|}
\hline \multirow[b]{3}{*}{ Mycobacterium species } & \multicolumn{4}{|c|}{ Primers } \\
\hline & \multicolumn{3}{|c|}{ Conventional PCR } & \multirow{2}{*}{$\begin{array}{c}\text { Real-time } \\
\text { PCR }\end{array}$} \\
\hline & IS6110 & $\begin{array}{l}\text { IS41/ } \\
\text { IS43 }\end{array}$ & IS6110_T & \\
\hline M. bovis & + & + & + & + \\
\hline M. terrae & + & + & & \\
\hline M. goodii & + & + & + & \\
\hline M. fortuitum & & + & & \\
\hline \multicolumn{5}{|l|}{ M. kansasii } \\
\hline \multicolumn{5}{|l|}{$\begin{array}{l}\text { M. avium subsp. } \\
\text { Paratuberculosis }\end{array}$} \\
\hline M. wolinskyi & + & + & + & + \\
\hline \multicolumn{5}{|l|}{ M. simiae } \\
\hline M. peregrinum & + & & & \\
\hline \multicolumn{5}{|l|}{ M. intracellulare } \\
\hline M. chelonae & + & & & \\
\hline \multicolumn{5}{|l|}{ M. avium subsp avium } \\
\hline M. smegmatis & & & & \\
\hline
\end{tabular}

\section{Establishing assay conditions}

The limit of detection for IS6110_T was $100 \mathrm{fg}$ of $M$. bovis DNA. The limit of detection was determined using serial dilutions of $M$. bovis DNA. Clinical tissue samples will contain bovine (or other species being tested) DNA that may inhibit the real-time PCR reaction. To determine the effect of non-target DNA on the real-time PCR reaction, increasing amounts of bovine DNA was spiked with M. bovis DNA. M. bovis was detectable in up to $1 \mu \mathrm{g}$ of bovine DNA. At $2 \mu \mathrm{g}$ of bovine DNA inhibition of the PCR was detected.

To test the utility of this assay to detect $M$. bovis in clinical samples, DNA was isolated from tissue homogenates that were culture positive for $M$. bovis or M. smegmatis. Real-time PCR using primers for M. bovis and bovine $\beta$-actin was performed on each sample in duplicate. $\beta$-actin served as a control to detect inhibition of the PCR reaction. A sample was considered positive when a PCR product was detected in both duplicates from $\beta$-actin and IS6110. Initial studies using both conventional and real-time PCR assays only detected 2/10 and $1 / 10$ samples respectively. It was hypothesized that the low level of detection was due to relatively little $M$. bovis DNA relative to bovine DNA present in samples. To test this hypothesis, DNA from 4 homogenized tissues that were culture positive for $M$. bovis and one that was culture positive for M. smegmatis were chosen. Real-time PCR reactions were prepared with increasing amounts of DNA from these samples (100 ng to 1000 ng). One of the four $M$. bovis culture positive samples was PCR positive when $100 \mathrm{ng}$ and two of four when 250 ng of DNA was used in the PCR reaction (Table 2). Increasing DNA concentration did not result in detection of the remaining samples.

To increase the sensitivity of the assay, a nested PCR strategy was developed. Initially, conventional PCR was performed using primer IS41 and the IS6110_T reverse primer to generate a 334 base pair product that encompasses the region targeted by the real-time PCR assay. Five microliters of the initial PCR reaction was used as the template in the real-time PCR assay. The samples described above were tested using the nested assay. $M$. bovis DNA was detected in all four of the samples from infected tissues.

\section{Detection of $M$. bovis in tissues from naturally infected animals}

Additional tissue homogenates were obtained to test the diagnostic potential of this assay. DNA was isolated from tissues of $M$. bovis infected cattle $(\mathrm{n}=30)$ and non-M. bovis infected animals $(\mathrm{n}=18)$. Of the $30 \mathrm{M}$. bovis culture positive tissues 20 were PCR positive; whereas, no PCR product was detected in the non- $M$. bovis infected tissues (Table 3). 
Table 2 Results of increasing starting DNA on real-time PCR assay performance

\begin{tabular}{|c|c|c|c|c|c|c|c|c|c|c|}
\hline \multirow[b]{3}{*}{ DNA $^{c}$} & \multicolumn{10}{|c|}{ Sample } \\
\hline & \multicolumn{2}{|c|}{$01916^{a}$} & \multicolumn{2}{|c|}{$4022^{a}$} & \multicolumn{2}{|c|}{$4477^{b}$} & \multicolumn{2}{|c|}{$01870^{a}$} & \multicolumn{2}{|c|}{$04034^{a}$} \\
\hline & IS6110_T & $\beta$-actin & IS6110_T & $\beta$-actin & IS6110_T & $\beta$-actin & IS6110_T & $\beta$-actin & IS6110_T & $\beta$-actin \\
\hline 100 & + & + & - & + & - & + & - & + & - & + \\
\hline 250 & + & + & + & + & - & + & - & + & - & + \\
\hline 500 & + & + & + & + & - & + & - & + & - & + \\
\hline 1000 & + & + & + & + & - & + & - & + & - & + \\
\hline
\end{tabular}

\section{Discussion}

A number of factors may affect the ability of a PCR based test to be successful. Uncharacterized PCR inhibitors can be carried over from DNA isolation procedures from blood and tissues. Although these may be a cause of concern, they are irrelevant if primers and probes with sufficient specificity are not available. Environmental mycobacteria present in lymph nodes submitted for diagnostic testing can confound assays that lack sufficient specificity. Detection of $M$. tuberculosis complex species using primers to IS6110 is well established; as evidenced by the large number of publications referencing the original publication by Eisenach et al. [2]. In the USA, IS6110 is the diagnostic target used at National Veterinary Services Laboratories for detection of $M$. bovis in fixed tissues $[3,4]$. Most publications testing the specificity of the method of Eisenach et al. are designed to detect $M$. tuberculosis with specificity being tested against mycobacteria thought to be common in humans. Because cattle may be infected with a different subset of non-tuberculous mycobacteria than those infecting humans, we sought to determine if established PCR protocols targeting IS6110 would be appropriate for strains isolated from cattle in the USA. In the present study, Eisenach et al. primers cross-reacted with mycobacteria other than $M$. tuberculosis complex species (Table 1). Redesign of the primers and the addition of a probe increased the specificity against strains commonly isolated from cattle in the USA.

Cross-reactivity to $M$. wolinskyi remained after redesign of the probe used in the real-time PCR reaction. Sequencing of the region targeted by the IS6110 primers and probes revealed that the region was identical between $M$. bovis and $M$. wolinskyi. The region of the

Table 3 Results of real-time PCR using IS6110_T to detect $M$. bovis in diagnostic samples

\begin{tabular}{lcc}
\hline & \multicolumn{2}{c}{ Culture Results } \\
\hline Result from PCR assay & M. bovis & Non- $\boldsymbol{M}$. bovis \\
\hline Positive & 20 & 0 \\
Negative & 10 & 18 \\
\hline
\end{tabular}

IS6110 that is targeted by these primers is in the 5' region of the transposase gene, which may be common between IS6110 and another insertion sequence in $M$. wolinskyi. The 16S gene of the $M$. wolinskyi sample used in this study was sequenced to confirm the identity of the isolate. The impact of this cross reactivity will be relatively minor since $M$. wolinskyi was only isolated 3 times between 2004 and October 2010.

Thirty $M$. bovis infected and 18 non- $M$. bovis infected tissues were used to test the utility of this assay. None of the tissues from non- $M$. bovis infected animals were positive by PCR. Although the sample size is small the apparent specificity is $100 \%$ (95\% CI, 44.1\%-89.5\%).

This assay detected $M$. bovis DNA in 20 of the 30 culture positive samples tested, with an apparent sensitivity of 66.7\% (95\% CI, 47.2\%-82.7\%). Several methodologies have previously been employed to increase sensitivity. Parra et al. used a capture probe to isolate mycobacterial DNA from tissue homogenates [5] achieving a similar sensitivity (65.6\%) to that reported here. Taylor et al. reported a sensitivity of $70 \%$ when performing PCR directly on tissue homogenates, but increased the sensitivity to $91 \%$ when PCR was only performed on DNA isolated from lesions excised from the tissues rather than whole tissue homogenates [6]. The limitation of this method is that the assay can only be performed on tissues that have visible lesions, thus excluding samples without readily apparent lesions.

\section{Conclusions}

The use of a PCR assay to detect M. bovis in tissue homogenates may provide a more rapid method for providing diagnostic test results to field veterinarians than culture. The IS6110_T real-time PCR assay provides increased specificity over previously published IS6110 assays with a sensitivity of $66.7 \%$. A large-scale study is needed to determine if the sensitivity of the assays are adequate for the Bovine TB Eradication Program in the USA.

\section{Methods}

\section{Mycobacterial Strains}

The following reference strains obtained from ATCC: M. smegmatis (ATCC 35797), M. terrae (ATCC 15755), 
M. goodii (ATCC 700504), M. fortuitum (ATCC 6841), M. kansasii (ATCC 12478), M. wolinskyi (ATCC 700010), M. simiae (ATCC 25275), M. peregrinum (ATCC 14467), M. intracellulare (ATCC 13950) and $M$. chelonae (ATCC 35752). M. bovis, M. avium, and M. avium subspecies paratuberculosis were well characterized clinical field isolates. Mycobacteria were grown in grown in Middlebrook 7H9 medium supplemented with $10 \%$ oleic acid-albumin-dextrose complex (Becton Dickinson Microbiology Systems, Franklin Lakes, NJ. Mycobactin J was added to culture media when growing $M$. paratuberculosis. DNA was isolated using the following method. Mycobacteria from $1.5 \mathrm{ml}$ o f culture were washed once with $1 \times$ Tris-EDTA (TE) buffer and resuspended in $500 \mu \mathrm{l} \mathrm{TE}$. Twenty microliters of $100 \mathrm{mg} / \mathrm{ml}$ Lysozyme (Sigma, St. Louis, MO) was added and incubated for a minimum of 3 hours or overnight at $37^{\circ} \mathrm{C}$. SDS was added to a final concentration of $1 \%$ followed by the addition of $150 \mu \mathrm{g}$ of Proteinase K (Roche Applied Science, Indianapolis, IN) and incubated for 3 hours at $65^{\circ} \mathrm{C}$. Following protein digestion, $100 \mu \mathrm{l}$ of 5 $\mathrm{M} \mathrm{NaCl}$ was added. One hundred microliters of CTAB/ $\mathrm{NaCl}$ (274 mM hexadecyltrimethylammonium bromide/ $0.7 \mathrm{M} \mathrm{NaCl}$, Sigma). The resulting solution was mixed thoroughly by inverting tube then incubated at $65^{\circ} \mathrm{C}$ for 10 minutes. An equal volume of Phenol/chloroform/isoamyl alcohol (25:24:1) was added and an emulsion formed by vortexing then centrifuged at $16,000 \times \mathrm{g}$ for 5 minutes at room temperature.

The aqueous phase was removed to a fresh tube and equal volume of isopropanol was added and the samples were placed at $-80^{\circ} \mathrm{C}$. Precipitated DNA was collected by centrifugation at $16,000 \times \mathrm{g}$ for 150 minutes at $4^{\circ} \mathrm{C}$. The isopropanol was removed and $1 \mathrm{ml}$ of ice-cold $70 \%$ ethanol was added. The sample was centrifuged at $16,000 \times \mathrm{g}$ for 5 minutes and the ethanol removed. The samples were then dried at room temperature until dry. The DNA pellet was resuspended in PCR grade water.

\section{Isolation of DNA from fresh tissues}

Forty-eight (42 bovine, 5 cervine, 1 porcine) homogenized lymph nodes submitted as part of USDA's National Bovine Tuberculosis Eradication Program were obtained from the Mycobacteria and Brucella Section at the National Veterinary Services Laboratories during 2005 and 2006. Homogenization and decontamination of tissues was performed according to established protocols [7] in preparation for recovery of $M$. bovis by culture. Homogenates not used to inoculate culture media were frozen at $-80^{\circ} \mathrm{C}$ until used in PCR assays. Five hundred microliters of the homogenate was heat inactivated by incubating the sample in a screw-topped microcentrifuge tube at $80^{\circ} \mathrm{C}$ for 40 minutes. After 20 minutes the sample was mixed. Particulate matter (including mycobacteria) was collected by centrifuging the sample for 10 minutes at $13,000 \times \mathrm{g}$. The supernatant was discarded and the pellet resuspended in $500 \mu \mathrm{l}$ ASL buffer (Qiagen, Valencia, CA) followed by a 5 min incubation at $95^{\circ} \mathrm{C}$. After cooling to $56^{\circ} \mathrm{C}, 125 \mu \mathrm{g}$ of Proteinase $\mathrm{K}$ (Sigma, St. Louis, MO) was added to samples. Buffer AL (Qiagen) was then added and the sample was incubated overnight at $56^{\circ} \mathrm{C}$. Liberated DNA was isolated using the Qiamp Blood Mini Kit according to the manufacturer's directions except that $500 \mu \mathrm{l}$ of cold $100 \%$ ethanol was added before the sample was applied to the column.

\section{Detection of mycobacterial DNA by conventional PCR}

The following primer pairs were tested IS41/43 [1], IS6110 [2], and primers designed in house IS6110_T forward (5'-AGTTTGGTCATCAGCCGTTC-3') and IS6110_T reverse (5'-CGAACTCAAGGAGCACATCA3') using Primer3 [8]. The following optimized protocols were used with $50 \mu \mathrm{l}$ PCR reactions.

IS41/43: A $50 \mu \mathrm{l}$ reaction was prepared using $1 \times \mathrm{PCR}$ reaction buffer (final $\mathrm{MgCl}_{2} 2 \mathrm{mM}$ ), $1 \mathrm{U}$ FastStart Taq, $2.5 \mathrm{mM}$ each dNTP's (Roche), $5 \mu \mathrm{g}$ BSA (Ambion), 2.5 pmol of each primer, and with $0.5 \mu$ DNA. A touch down PCR method was used to reduce false priming and increase specificity. The following conditions were used: an initial activation step of $94^{\circ} \mathrm{C}$ for $2 \mathrm{~min}$. The following cycle was repeated 7 times: $94^{\circ} \mathrm{C}$ for $45 \mathrm{sec}-$ onds, $72^{\circ} \mathrm{C}$ for $1 \mathrm{~min}\left(-1^{\circ} \mathrm{C} /\right.$ cycle $)$, then $72^{\circ} \mathrm{C}$ extension for $2 \mathrm{~min}$. Amplification was continued by cycling through the following conditions for an additional 28 times: $94^{\circ} \mathrm{C}$ for 1 minute, $65^{\circ} \mathrm{C}$ for 1 min then $72^{\circ} \mathrm{C}$ for $2 \mathrm{~min}$. A final $10 \mathrm{~min}$ extension was performed.

IS6110_T: $50 \mu \mathrm{l}$ reactions were prepared as for the IS41/ 43 primers except that 1 pmol of each primer was added. PCR with these primers was performed using the following thermocycler conditions: an initial activation step of $94^{\circ} \mathrm{C}$ for $2 \mathrm{~min}$. The following cycle was repeated 14 times: $94^{\circ} \mathrm{C}$ for 45 seconds, $65^{\circ} \mathrm{C}$ for $1 \mathrm{~min}\left(-1^{\circ} \mathrm{C} /\right.$ cycle $)$, then $72^{\circ}$ $\mathrm{C}$ extension for $2 \mathrm{~min}$. Amplification was continued by cycling through the following conditions an additional 28 times: $94^{\circ} \mathrm{C}$ for 1 minute, $50^{\circ} \mathrm{C}$ for $1 \mathrm{~min}$ then $72^{\circ} \mathrm{C}$ for 2 min. A final 10 min extension was performed.

IS6110 Primers: A $50 \mu \mathrm{l}$ reaction was prepared with the following components: $1 \times$ Gene Amp PCR Buffer II (final $\mathrm{MgCl}_{2}$ concentration $2.5 \mathrm{mM}$ ), $1.25 \mathrm{U}$ AmpliTaq Gold (Applied Biosystems), $2.5 \mathrm{mM}$ each dNTP (Roche), 2.5 pmol each primer, and $0.5 \mu \mathrm{l}$ template.

All PCR products were analyzed on a $1.5 \%$ agarose gel (Invitrogen) stained with ethidium bromide and visualized with a Bio-Rad Gel Doc XR.

\section{Detection of mycobacterial DNA by real-time PCR}

Detection of Mycobacterial DNA by real-time PCR was performed using the IS6110_T primers and a 5' Hex 
labeled probe (5'-AGCCACACTTTGCGGGCACC-3') with a 3' Iowa Black FQ quencher (Integrated DNA Technologies). Taqman Universal PCR Mastermix (Applied Biosystems) was used according to the manufacturer's directions with a final primer concentration of $0.4 \mu \mathrm{M}$ each and $0.1 \mu \mathrm{M}$ probe. The real-time PCR was run in an ABI7500. Detection of $\beta$-actin was used as a PCR control.

\section{Detection of $\beta$-actin}

PCR reactions to detect mammalian $\beta$-actin were performed parallel with each sample. The primers 5'TCCCTGGAGAAGAGCTACGA -3' and 5'- AGGAAGGAAGGCTGGAAGAG -3' and FAM labeled probe 5'TCACCATCGGCAATGAGCGG -3' with a 3' Iowa Black FQ quencher (Integrated DNA Technologies) were designed using Primer3Plus [9]. $\beta$-actin PCR was performed as described for IS6110_T. $\beta$-actin was included as a positive control for the PCR reaction and to detect successful DNA extraction from tissue homogenates. Lack of amplification was assumed to indicate that the PCR reaction was inhibited. For a sample to be considered positive PCR products from both the IS6110 PCR and $\beta$-actin PCR needed to occur.

\section{Nested real-time PCR}

The initial outside PCR reaction was carried out as described for IS6110_T (conventional PCR) except 2.5 pmol of the primers IS41 and IS6110_T reverse with 5 $\mu \mathrm{g}$ bovine serum albumin (Ambion). The second step was carried out as described above.

\section{Sequencing}

IS6110 Products: PCR products were excised from a $1 \%$ agarose gel after electrophoresis. The PCR products were extracted from the gel and purified using a Gel extraction Kit (Qiagen) according to the manufacturer's instructions. Sequencing was performed by the Genomics facility at the National Animal Disease Center using standard techniques.

16S Gene: Primers T39 and T13 from Talaat et al. [10] were used to PCR amplify a portion of the $16 \mathrm{~S}$ Gene. The PCR product was purified using a MinElute PCR Purification Kit (Qiagen) according to the manufacturer's instructions. The purified product was sequenced as above. The sequence was identified as $M$. wolinskyi using the Ridom Databse with 100\% identity [11].

\section{Statistical analysis}

Calculation of the diagnostic specificity and sensitivity along with 95\% confidence intervals (CI) were done using epiR package (version 0.9-26) in $\mathrm{R}$ (version 2.11.1) [12].

\section{Acknowledgements}

The authors would like to thank Rachel Huegel for her devoted work on this project.

\section{Author details}

${ }^{1}$ Infectious Bacterial Diseases Research Unit, National Animal Disease Center Agricultural Research Service, United States Department of Agriculture, Ames, lowa, USA. ${ }^{2}$ Mycobacteria and Brucella Section, National Veterinary Services Laboratories, United States Department of Agriculture, Ames, lowa, USA.

\section{Authors' contributions}

TCT conceived the study, participated in its design, data acquisition and analysis, and wrote the paper. $\mathrm{BH}$ participated in design of the study and data analysis. MVP and WRW participated in study design and data interpretation. All authors read and approved the final manuscript.

Received: 3 November 2010 Accepted: 25 August 2011

Published: 25 August 2011

\section{References}

1. Plikaytis BB, Eisenach KD, Crawford JT, Shinnick TM: Differentiation of Mycobacterium tuberculosis and Mycobacterium bovis BCG by a polymerase chain reaction assay. Mol Cell Probes 1991, 5:215-219.

2. Eisenach KD, Cave MD, Bates JH, Crawford JT: Polymerase chain reaction amplification of a repetitive DNA sequence specific for Mycobacterium tuberculosis. J Infect Dis 1990, 161:977-981.

3. Miller J, Jenny A, Rhyan J, Saari D, Suarez D: Detection of Mycobacterium bovis in formalin-fixed, paraffin-embedded tissues of cattle and elk by PCR amplification of an IS6110 sequence specific for Mycobacterium tuberculosis complex organisms. J Vet Diagn Invest 1997, 9:244-249.

4. Miller JM, Jenny AL, Payeur JB: Polymerase chain reaction detection of Mycobacterium tuberculosis complex and Mycobacterium avium organisms in formalin-fixed tissues from culture-negative ruminants. Vet Microbiol 2002, 87:15-23.

5. Parra A, García N, García A, Lacombe A, Moreno F, Freire F, Moran J, Hermoso de Mendoza J: Development of a molecular diagnostic test applied to experimental abattoir surveillance on bovine tuberculosis. Vet Microbiol 2008, 127:315-324.

6. Taylor GM, Worth DR, Palmer S, Jahans K, Hewinson RG: Rapid detection of Mycobacterium bovis DNA in cattle lymph nodes with visible lesions using PCR. BMC Vet Res 2007, 3:12.

7. Hines N, Payeur JB, Hoffman LJ: Comparison of the recovery of Mycobacterium bovis isolates using the BACTEC MGIT 960 system, BACTEC 460 system, and Middlebrook $7 \mathrm{H} 10$ and $7 \mathrm{H} 11$ solid media. J Vet Diagn Invest 2006, 18:243-250.

8. Rozen S, Skaletsky HJ: Primer3 on the WWW for general users and for biologist programmers. In Bioinformatics Methods and Protocols: Methods in Molecular Biology. Edited by: Krawetz S, Misener S. Totowa, NJ: Humana Press: 2000:365-386.

9. Untergasser A, Nijveen $H$, Rao X, Bisseling $T$, Geurts $R$, Leunissen JA Primer3Plus, an enhanced web interface to Primer3. Nucleic Acids Res 2007, 35:W71-74

10. Talaat AM, Reimschuessel R, Trucksis M: Identification of mycobacteria infecting fish to the species level using polymerase chain reaction and restriction enzyme analysis. Vet Micro 1997, 58:229-237.

11. Harmsen D, Rothgänger J, Frosch M, Albert J: RIDOM: Ribosomal Differentiation of Medical Microorganisms Database. Nucleic Acids Res 2002, 30:416-417.

12. Team RDC: $R$ : A language and environment for statistical computing Viena, Austria: R Foundation for Statistical Computing; 2010.

doi:10.1186/1746-6148-7-50

Cite this article as: Thacker et al.: Improved specificity for detection of Mycobacterium bovis in fresh tissues using IS6110 real-time PCR. BMC Veterinary Research 2011 7:50 